\title{
Novos agentes na reconfiguração econômica do território fluminense no início do século XXI: os investimentos chineses no estado do Rio de Janeiro
}

New agents in the territory's economic reconfiguration fluminense at the beginning of the 21st century: Chinese investments in the State of Rio de Janeiro Nuevos agentes en la reconfiguración económica del territorio fluminense a comienzos del siglo XXI: las inversiones chinas en el estado de Rio de Janeiro Des nouveaux acteurs dans la réconfiguration économique: les investissements chinois dans le territoire fluminense au début du XXIème siècle

\section{Thiago Jeremias Baptista}

\section{(2) OpenEdition}

\section{Journals}

\section{Edição electrónica}

URL: http://journals.openedition.org/espacoeconomia/1401

DOI: 10.4000/espacoeconomia.1401

ISSN: 2317-7837

\section{Editora}

Núcleo de Pesquisa Espaço \& Economia

Refêrencia eletrónica

Thiago Jeremias Baptista, « Novos agentes na reconfiguração econômica do território fluminense no início do século XXI: os investimentos chineses no estado do Rio de Janeiro », Espaço e Economia [Online], 5 | 2014, posto online no dia 29 dezembro 2014, consultado o 11 junho 2020. URL : http:// journals.openedition.org/espacoeconomia/1401; DOI : https://doi.org/10.4000/espacoeconomia. 1401

Este documento foi criado de forma automática no dia 11 junho 2020.

(C) NUPEE 


\section{Novos agentes na reconfiguração econômica do território fluminense no início do século XXI: os investimentos chineses no estado do Rio de Janeiro}

New agents in the territory's economic reconfiguration fluminense at the beginning of the 21st century: Chinese investments in the State of Rio de Janeiro Nuevos agentes en la reconfiguración económica del territorio fluminense a comienzos del siglo XXI: las inversiones chinas en el estado de Rio de Janeiro Des nouveaux acteurs dans la réconfiguration économique: les investissements chinois dans le territoire fluminense au début du XXIème siècle

Thiago Jeremias Baptista

\section{Introdução}

1 O artigo evidencia a projeção do Brasil como um dos maiores receptores de investimentos na América Latina, destacando o ingresso do capital sínico no país nesse início do presente século. Tais investimentos caracterizam o influxo de investimentos chineses no território fluminense como novo agente na reestruturação produtiva do território. Nesse sentido, sinalizamos que no início do século XXI, o Brasil ascendeu como um dos maiores receptores de investimentos oriundos da República Popular da China (RPC), o novo líder do renascimento econômico da Ásia Oriental (ARRIGHI, 2008). Embora, houvesse este tipo de investimento em momentos anteriores a referida época, os mesmos não possuíam vulto tão relevante quanto à trajetória apresentada no período 2008-2010, quando a RPC intensificando a incorporação das trocas com o Brasil 
às necessidades da sua economia, elevou consideravelmente os investimentos neste país sul-americano.

Convergimos com Santos (2008), ao assinalar que "o papel das finanças na produção de uma nova arquitetura do espaço não tem escapado aos geógrafos" (SANTOS, 2008, p. 201). E compreendendo a globalização como um processo histórico (HARVEY, 2004; CASTRO, 2013), identificamos que sua fase contemporânea é marcada pela internacionalização das trocas e do comércio, reorganizações geográficas, busca dos “ajustes espaciais" pelo capitalismo, desregulamentação financeira e descentralização do sistema monetário internacional (HARVEY, 2004). Concedemos ênfase nesse estudo à desregulamentação financeira, haja vista que se valendo da densidade técnica e científica proveniente da afirmação do meio técnico-científico-informacional (SANTOS, 2008) a mobilidade do capital é garantida no sistema de livre iniciativa.

Para Arrighi (2012) o sistema de livre iniciativa, iniciado na década de 1970, com a crise da hegemonia americana e o crescimento das transnacionais reorganizando os processos produtivos, cria um ambiente em que as empresas transnacionais não se submetem a nenhuma autoridade estatal tendo "o poder de submeter as suas próprias 'leis' todo e qualquer membro do sistema interestatal" (ARRIGHI, 2012, p.74). Segundo Arrighi (2012), a partir do último quartel do século XX tem-se como principais aspectos a "internalização das relações internacionais dentro das próprias formas institucionais do capitalismo global" (ARRIGHI, 2012, p.81). Tendência pela qual os laços econômicos transnacionalizados criam uma região não territorial na economia mundial, correspondendo ao "aumento explosivo do número de empresas multinacionais e das transações dentro dela e entre elas tornou-se o fator mais crucial do definhamento do sistema de nações territoriais com sede primária no poder mundial" (ARRIGHI, 2012, p. 81). Com efeito, "o espaço-de-fluxos triunfa por não se identificar com nenhum Estado em particular, mas por construir organizações empresariais não territoriais que abrangiam o mundo inteiro" (ARRIGHI, 2012, p. 84).

Com a expansão da economia de mercado, ocorreu uma ampla internacionalização do capital. Assim, o espaço de reprodução do capital adquire novas condições de reprodução, seu espaço se amplia além das fronteiras nacionais, conferindo-lhe uma conotação internacional. A desregulamentação dos fluxos de capitais produtivos e especulativos em escala global no meio técnico-científico-informacional confere um poder ao capital e aos agentes hegemônicos da globalização contemporânea na identificação de espaços economicamente vantajosos à sua reprodução.

Para Ianni (1996) na época dos mercados mundiais de capitais, quando as mais diversas formas de capital passam a movimentar-se de modo cada vez mais acelerado e generalizado e todas as instâncias ditas nacionais veem reduzidas suas capacidades de controlar os movimentos de capital. Segundo Harvey (2004) nesse processo um elemento importante é a mudança do papel do Estado na economia, que perdeu alguns de seus poderes tradicionais de controle da mobilidade do capital. Por conseguinte, as operações do Estado passaram a ser disciplinadas pelo capital monetário e financeiro num grau inaudito, e o Estado viu-se reduzido ao papel de criar um clima favorável aos negócios. Portanto, diferente daquela concepção em que "o território era a base, o fundamento do Estado-Nação que, ao mesmo tempo, o moldava. Hoje, quando vivemos uma dialética do mundo concreto, evoluímos da noção tornada antiga de Estado Territorial, para a noção pós-moderna de transnacionalização do território" (SANTOS, 1996, p. 15). 
6 Segundo Santos (1996) encontramos hoje no território novos recortes além da categoria região, assim como o novo funcionamento do território através das horizontalidades e verticalidades. Nesse sentido, o influxo do capital sínico no Brasil no início do século XXI, nos permite identificar na verticalidade decorrente da atuação de pontos distantes que se articulam através do direcionamento de investimentos chineses à área do território fluminense, e nesta os recortes espaciais municipais e cidades onde se materializam as ações de novos agentes hegemônicos que imprimem o uso de áreas do território segundo a lógica do capitalismo de estado oriental.

7 Santos (2008) sinaliza que "os atores hegemônicos da vida econômica, social e política podem escolher os melhores lugares para sua atuação e, em consequência, a localização dos demais atores é condenada a ser residual" (SANTOS, 2008, p.204). Nesse contexto, é preciso ter claro, conforme nos revela Sobral (2013), "que o território se transforma em arena de negociação a respeito da geração e comando sobre o excedente econômico" (SOBRAL, 2013, p. 314), sobretudo, no momento em que o estado do Rio de Janeiro recebe um grande aporte de investimentos públicos e privados, como apontado por Oliveira (2013) e Terra et al (2013).

8 No limiar do século XXI, o fato do estado do Rio de Janeiro ingressar na rota dos fluxos de investimentos chineses conduz às análises de temáticas internacionais, econômicoregionais e urbano-produtivas a novos desafios, no sentido de realizar um exercício reflexivo e compreender o papel que esse fluxo de investimentos desempenha no processo de reestruturação territorial e na reconfiguração econômica do território fluminense. E assim, preencher lacunas ao considerar que a inserção de áreas do território do estado do Rio de Janeiro nas formas de organização e funcionamento de cadeias produtivas globais recebe além do capital estatal, capital privado nacional e transnacional, mais recentemente, a influência do capital sínico nesse processo, abrindo assim novas perspectivas de análise para a economia fluminense.

Compreendemos que a dinâmica econômica do território fluminense vem sendo caracterizada por uma retomada de suas taxas de crescimento econômico e aumento da participação no PIB brasileiro, sobretudo, capitaneadas por um processo de industrialização do seu interior, assim como pela chegada de investimentos industriais na periferia metropolitana e terciarização econômica do núcleo metropolitano. Processos que para Oliveira ${ }^{1}$, Silva (2012) e Sobral (2013), contribuem para o desenvolvimento econômico de diferentes regiões de governo do estado do Rio de Janeiro, apresentando transformações socioespaciais em diferentes escalas, bem como contribuem para a especialização regressiva. Evidenciam-se assim, processos que de certo modo, influenciados por fatores relacionados à tendência econômica contemporânea, como a terciarização das cidades-regiões e dos espaços metropolitanos e as novas lógicas de localização das atividades produtivas, rompem com os padrões locacionais orientados pela economia de aglomeração.

10 Portanto, busca-se através do artigo em tela compreender a inserção do estado do Rio de Janeiro como um dos maiores receptores de investimentos chineses no Brasil. Para isso, na primeira seção realiza-se uma apreciação básica do contexto tradicional da China, bem como são propostas considerações sobre a História das relações sinobrasileiras. Na segunda seção, evidencia-se a trajetória da RPC de receptora de investimentos em investidor internacional. Na terceira seção, a análise recai sobre a distribuição espacial dos investimentos chineses em diferentes escalas e o influxo desses investimentos no território fluminense, sua forma de ingresso e determinantes. 
Na quarta seção, espacializa-se os investimentos produtivos de origem chinesa no território a fim de relacionar esse novo agente atuante na reconfiguração econômica do estado como o processo de reestruturação produtiva do território fluminense nos últimos anos. Por fim, são traçadas as considerações finais do artigo em tela.

\section{A República Popular da China: localização e considerações sobre a História das relações sino- brasileiras}

11 Estabelecendo fronteiras com quinze países asiáticos, a China é o país mais populoso do mundo, localiza-se na porção oriental da Ásia (Imagem 1) e possui a terceira maior dimensão territorial mundial. Seu território compreende aproximadamente 9,6 milhões de $\mathrm{km}^{2}$, incluindo algumas ilhas que desde 1949, foram divididas entre a República Popular da China (que inclui a China continental, Hong Kong e Macau) e a República da China (que inclui Taiwan e algumas ilhas da província de Fujian).

Imagem 1 - Localização da República Popular da China

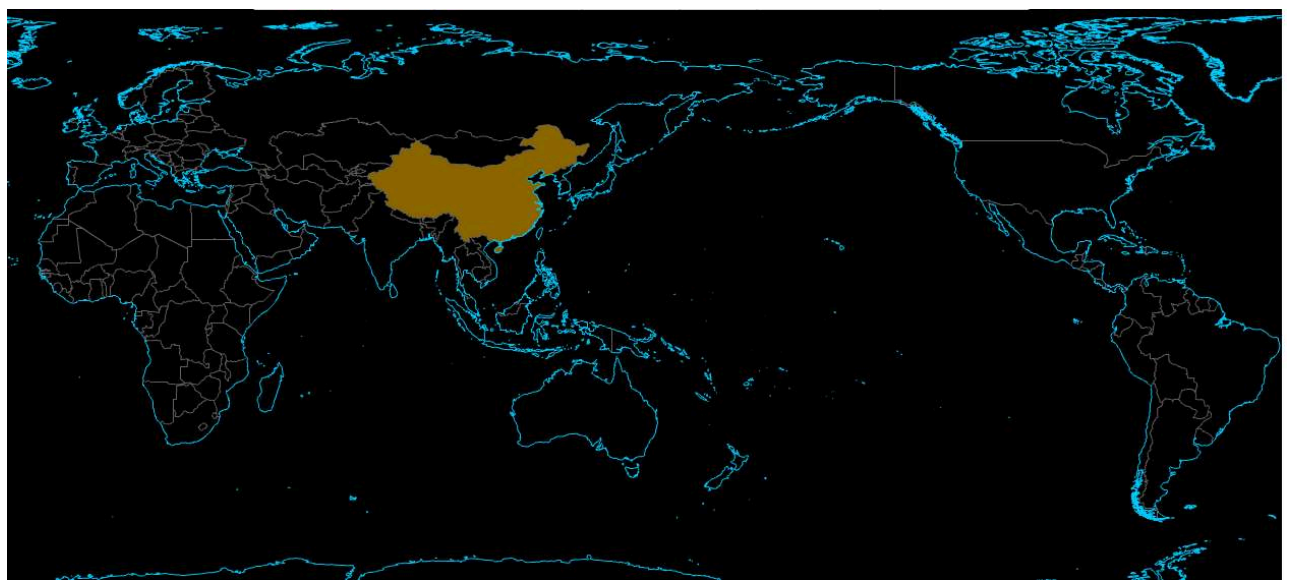

Fonte: http://www.ibge.gov.br/paisesat/main_frameset.php - acesso em 22 mai. 2013

12 Seguindo as recomendações de Kissinger (2011), quando aponta que qualquer tentativa de compreender o papel mundial da China no século XXI deve começar mesmo ao preço de uma possível simplificação excessiva por uma apreciação básica do contexto tradicional, compreendemos como relevante sinalizar que, de 221 a.C, sob a administração da Dinastia Qin, quando a China instituiu o seu império na Ásia, até o século XIX, quando foi submetida ao domínio britânico, o Império do Meio transitou do exercício da hegemonia regional ao século da humilhação (1842-1949) culminando no declínio de sua participação na economia mundial. o legado decorrente desse período implicou o atraso no processo de modernização econômica chinesa, levando o país oriental ao cenário de instabilidade no campo da política interna, em decorrência da disputa pelo poder entre os grupos políticos internos. Ainda diante desse desafio, a China assistiu à ocupação japonesa, travando batalhas em busca da emancipação da dominação territorial do país empreendida pelo Japão.

No que concerne às relações sino-brasileiras, o século XIX caracteriza-se como um ponto inflexão entre os dois países. Há que se salientar aqui, que as relações entre o 
Brasil e a China remontam ao referido século, quando a imigração de chineses para trabalharem na plantação de chá no Rio de Janeiro e suprir a falta de mão de obra depois da proibição do tráfico negreiro anteciparam a assinatura do Tratado SinoBrasileiro de Amizade, Comércio e Navegação (1880) e a abertura do consulado em Xangai (1883) que oficializaram as relações entre o Império brasileiro e o Império Manchu. Embora a aproximação política entre os referidos países tivesse sido iniciada e, alcançado grau de formalização, as relações comerciais e o fluxo de investimentos entre esses países eram baixos. Entretanto, um cenário mais delicado para as relações sino-brasileiras se projetaria com a Revolução Chinesa. Aproximando a República Popular da China da URSS na conjuntura geopolítica bipolar da Guerra Fria, a revolução de 1949 implicou o afastamento das negociações existentes entre o Brasil e a China ocasionando o rompimento das relações bilaterais e a abertura da embaixada brasileira na capital taiwanesa, Taipé. Tendo os dois países que aguardar a década de 1970 para realizarem o restabelecimento das relações políticas (1974) e promoverem cooperação mais intensa na área econômica após a assinatura do acordo comercial (1978).

Com efeito, diferentemente da conjuntura política decorrente da Revolução Chinesa (1949), que resultou no rompimento das relações sino-brasileiras estabelecidas em 1880, os governos de Brasília e Pequim dispõem, na atualidade, de um ambiente de concertação política favorável, efeito do amadurecimento das relações políticas e econômicas entre o Brasil e a China após o processo de restabelecimento de suas relações na década de 1970. Portanto, após quatro décadas os dois países desfrutam da consolidação de suas relações, o que pode ser visualizado através da assinatura de acordos de cooperação em diferentes áreas, estabelecimento de parcerias estratégicas (1993), criação da Comissão Sino-Brasileira de Alto Nível de Concertação e Cooperação (COSBAN) e do Plano de Ação Conjunta Brasil-China 2010-2014, bem como através das recíprocas visitas presidenciais. Foi em meio a essa conjuntura que a RPC se tornou o primeiro parceiro comercial em 2009, ascendendo como o principal destino das exportações brasileiras e afirmou-se em 2012, como o principal país de origem das importações brasileiras e dos principais investidores no Brasil.

Consideramos o ambiente de concertação política nas relações sino-brasileiras como uma condição favorável ao influxo de investimentos no território, avaliando que pelo lado da RPC, essa situação deve-se a tentativa do país asiático assegurar recursos estratégicos como as commodities energéticas e minerais, contribuindo para uma maior integração do país à economia internacional e exigindo do território fluminense uma reestruturação condizente a esse momento de dinamismo econômico.

\section{A República Popular da China: da abertura econômica a projeção como investidor internacional}

16 Embora, a Revolução Chinesa rompesse com o século da humilhação transformando-se num marco da história do país, e promovesse transformações políticas, sociais e econômicas na China, o cenário econômico ainda era marcado por reduzido dinamismo da economia nacional e baixas taxas de crescimento. Nem o malogrado projeto da Revolução Cultural Chinesa na década de 1960, foi capaz de impulsionar a modernização econômica. No entanto, foi com o programa das Quatro Modernizações implantado nos anos 1970-1980 por Deng Xiaoping que o país foi conduzido à sua fase ascensional. 
17 Essas reformas promoveram mudanças na política externa da RPC e conferiram ao país maior projeção internacional, dada à abertura econômica aos investimentos internacionais. Portanto, desde a década de 1970, devido à realização das políticas de modernização e abertura econômicas instituídas por Deng, "a China foi o primeiro país do bloco 'socialista' a abrir suas portas às empresas transnacionais (através do sistema joint ventures e das zonas econômicas especiais ou ZEEs instaladas a partir de 1980)" (COSTA, 2001, p. 200), apresentando uma trajetória de crescimento econômico que a conduziram, sobretudo, no ano de 2010 , à posição de segunda maior economia mundial e maior economia asiática. A fase ascensional da economia chinesa nas últimas décadas reflete, na atualidade, o efeito da construção de um socialismo com características especificamente chinesas conforme o idealizado por Deng Xiaoping, destacadamente quando este governante chinês promove a abertura da economia de seu país para o ingresso de capital externo.

18 Portanto, a ascensão da economia chinesa nas últimas quatro décadas é um fenômeno importante, despertando a atenção e motivando a realização de estudos por diferentes áreas, sobretudo, quando se identifica a passagem do país da condição de grande receptor para grande emissor de investimentos. Porém, como bem apontado por Oliveira (2012) destacamos que pouca tem sido a atenção conferida à República Popular da China como investidora. Nesse sentido, convergimos com Kaplan (2013) quando nos mostra que a economia mais vibrante do mundo vem ampliando sua influência territorial mais por meio do comércio, do que pela coação, e com Ribeiro (2013) ao apontar que a nova posição chinesa vem fazendo com que o país se expanda mundialmente, ampliando investimentos e fluxos financeiros dirigidos às economias periféricas detentoras de recursos naturais.

19 Segundo Geiger (2012) a atual política da China compartilha com os históricos países do centro capitalista o desenvolvimento da globalização. Assim, "a China vê sua participação na globalização como uma condição para o seu próprio desenvolvimento econômico e social que, no seu dizer, conduziria para uma economia de mercado socialista. Contando com densa participação nos intercâmbios internacionais de comércio e investimento" (GEIGER, 2012, p. 207). Portanto, cabe-nos não ignorar a participação dos investimentos chineses nas diferentes regiões do mundo e, sobretudo, no Brasil, país sul-americano que após 2010 passou a figurar como um dos maiores receptores de investimentos sínicos na América Latina.

No contexto de abertura econômica o território chinês caracterizou-se como um espaço para aplicação de investimentos e atuação do capital internacional com expectativa de lucro, condição que contribuiu para o crescimento econômico chinês a partir da década de 1980. No entanto, a República Popular da China tem como ponto de inflexão no que tange aos fluxos de investimentos o final da década de 1990 e o início dos anos 2000, momento em que ocorre um processo mais efetivo de incentivo à internacionalização das empresas chinesas ${ }^{2}$. Segundo Jabbour (2010), nesse período é que se dá a saída de capitais chineses para o exterior, algo que para o autor se conclui com o aumento de suas reservas cambiais e com a aquisição de ativos no exterior.

Os fluxos de investimento direto chinês no mundo multiplicaram-se por quase 30 vezes entre 1990 e 2007. Os montantes investidos por esse país passaram de US\$ 44 milhões em 1982 para US\$ 830 milhões em 1990, atingindo em 2007 a casa dos US\$ 22,5 bilhões. A aceleração desse crescimento foi maior a partir de 2003 e 2004 quando uma série de mudanças na política de incentivos à internacionalização e à simplificação de procedimentos foi implementada. A partir daí os investimentos 
realizados pela China suplantaram os investimentos no exterior de outros países da

Ásia em desenvolvimento (IPEA, 2011, p. 4).

$21 \mathrm{Na}$ atualidade, a China coloca-se como investidor externo (RIBEIRO, 2013). Em escala global merecem destaque a Ásia, a África e a América como as regiões que recebem os maiores aportes de investimentos sínicos (Imagem 2).

Imagem 2 - Distribuição geográfica dos investimentos chineses no mundo (Em bilhões de dólares)

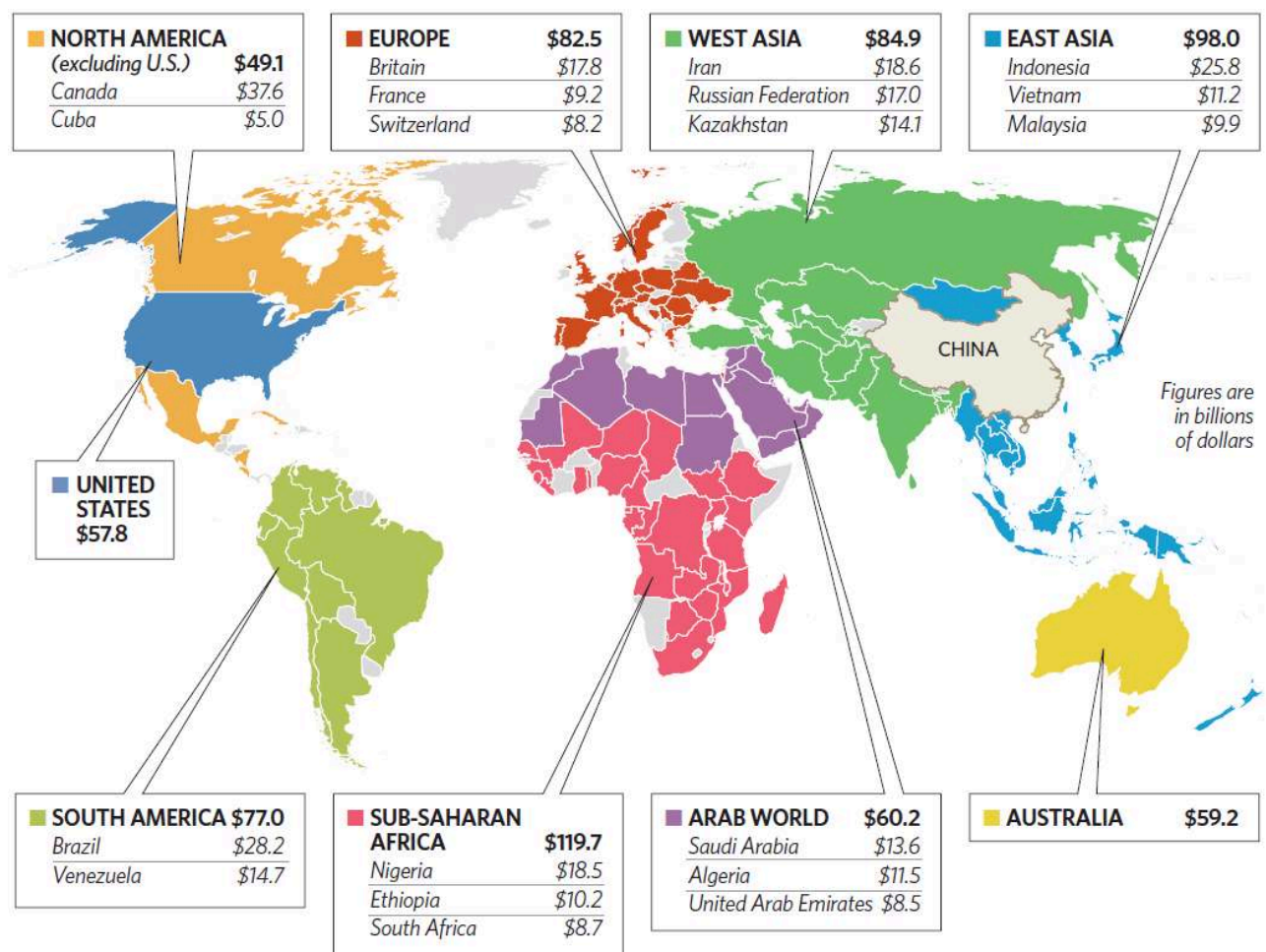

Fonte: http://www.heritage.org/ /media/Images/Reports/2013/07/ib3990_map1_825.ashx - Acesso em: 14 abr. 2014

Concordamos com Ribeiro (2013) quando sinaliza que o governo chinês e as empresas estatais vêm promovendo diversas abordagens em regiões que dispõem de amplos recursos naturais, como a África e a América Latina. Cujo interesse no acesso a recursos primários e energéticos vem motivando o estímulo à importação e expansão dos investimentos diretos em diversos países destas regiões. Boniface \& Védrine (2009) ao analisarem "o mundo visto pela China" (Imagem 3) destacam que este país asiático "interessa-se hoje [...] pela América Latina, para garantir a energia e as matérias primas que lhe faltam" (BONIFACE; VÉDRINE, 2009, p. 97). Com efeito, os recursos naturais sulamericanos contribuem para a inserção da região ao mercado global, como provedora de recursos naturais cada dia mais requeridos pelos países industrializados, e entre estes, tem-se a demanda do maior importador mundial de petróleo. Para Jabbour (2010) "os IEDs da China no exterior seguem um parâmetro bem previsível pelo menos no aspecto da busca de energia" (JABBOUR, 2010, p. 249). Para Fiori (2007) "de todos os pontos de vista, portanto, a China vem cumprindo um papel novo e fundamental na economia sul-americana" (FIORI, 2007, p. 98). Como efeito, Almeida (2011, p. 42) sinaliza que "a fortíssima demanda chinesa por alimentos e matérias primas chegou a ponto de reverter à situação de baixas cotações registradas pelas commodities nos anos 90 do século passado". 


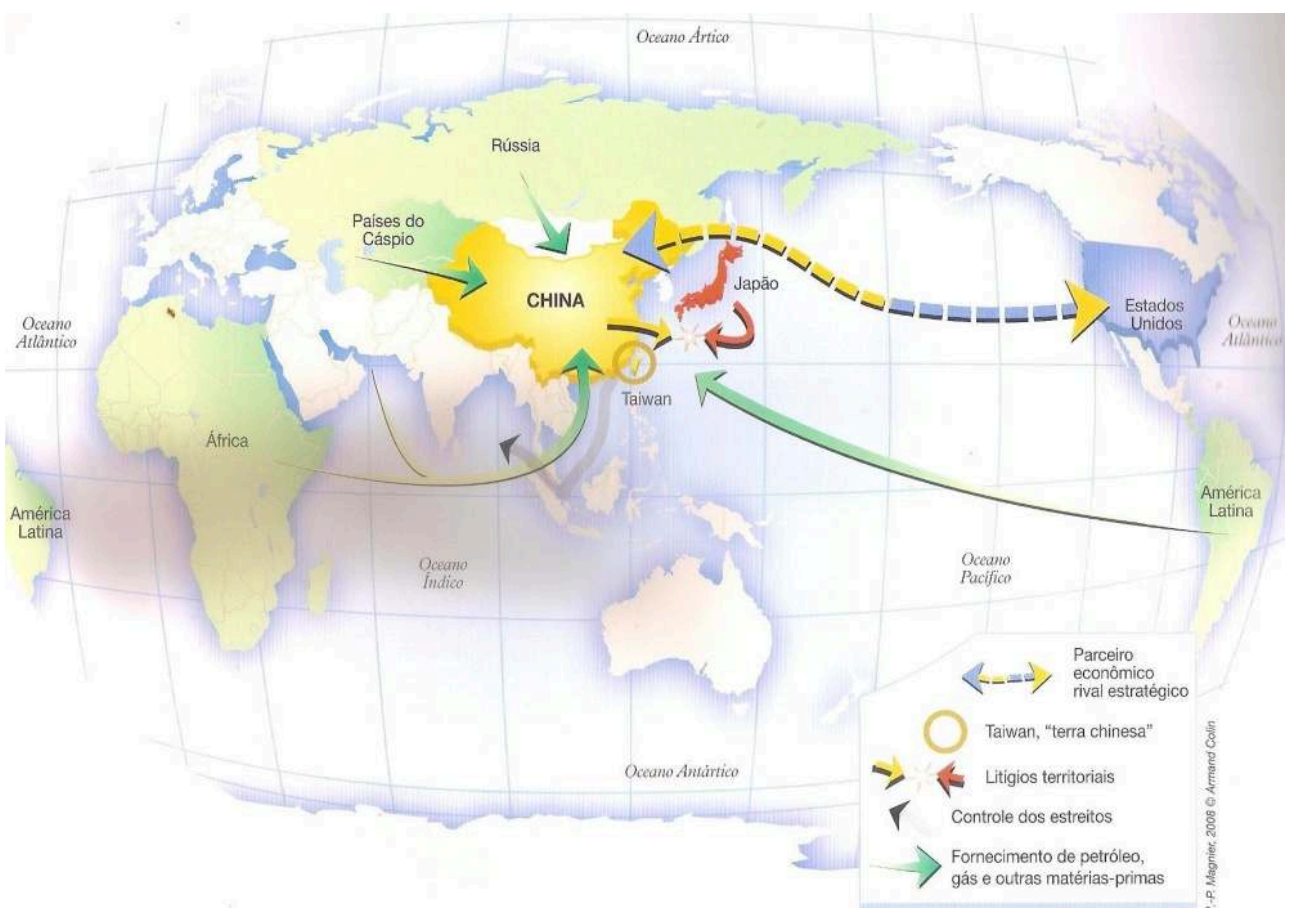

Fonte: Boniface \& Védrine (2009)

Para Kaplan (2013, p. 225) “a China está lançando mão de todas as formas de seu poder nacional - político, diplomático, econômico, comercial, militar e demográfico - para se expandir para além de suas fronteiras legais". No que concerne aos países de seu entorno, essas relações abrangem tanto a diplomacia, como às áreas comercial e militar, entretanto, no que tange à América do Sul, e em especial ao Brasil, sente-se a influência chinesa mais expressivamente, no campo diplomático e econômico financeiro-comercial. Entretanto, não são muitos os estudos voltados à avaliação dos investimentos chineses em território nacional, destacando-se nesse sentido os relatórios realizados pelo Centro Empresarial Brasil China (CEBC), o Relatório Nacional de Informações sobre o Investimento (Renai), Oliveira (2012) e o Ipea (2011). Assim o artigo em tela traz como contribuição, além da espacialização dos investimentos chineses na escala global e nacional - temática bem avaliada por outros estudos - a espacialização do influxo dos investimentos chineses no território fluminense.

\section{Os investimentos chineses em diferentes escalas e o influxo desses investimentos no território fluminense}

O exercício analítico da distribuição espacial dos investimentos da segunda maior economia mundial na escala global (Imagem 4), permite inferir que, atualmente, a RPC afirma-se como um importante investidor internacional, merecendo destaque a Ásia, a África e a América como as regiões que recebem os maiores aportes de investimentos sínicos, cujo objetivo consiste em atuar em diferentes áreas como atividades 
industriais, serviços e cultura, somando-se ainda a busca por recursos estratégicos a aquisição de novos mercados para os produtos chineses.

Imagem 4 - Evolução histórica do IED chinês no mundo (2007-2010)

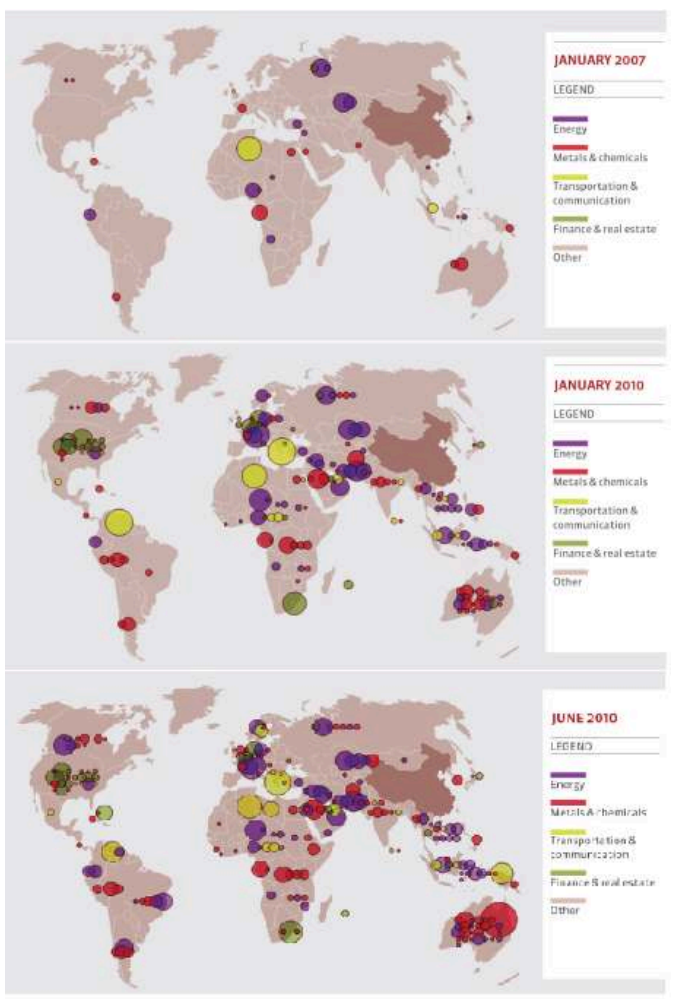

FONTE: HERITAgE FOUNDATION APUD CEBC, 2011

Sobre a temática do ingresso dos investimentos sínicos no Brasil compreendemos que:

"O Brasil representava, ainda, uma fronteira a ser alcançada pelos interesses daquela economia. Essa fronteira foi finalmente superada no ano de 2010, quando, assistimos a um expressivo aumento dos anúncios de investimentos chineses no país, momento em que a China passou a incorporar as trocas com o Brasil às necessidades da sua economia" (CEBC, 2011, p. 20).

Embora o início do século XXI fosse marcado pela entrada de investimentos chineses no país, estes não apresentaram até 2010 tanta expressividade, sendo crescente o fluxo de investimentos chineses para o Brasil entre os anos 2008-2010 (Imagem 5). 
Imagem 5 - Investimento externo direto (IED) chinês no Brasil

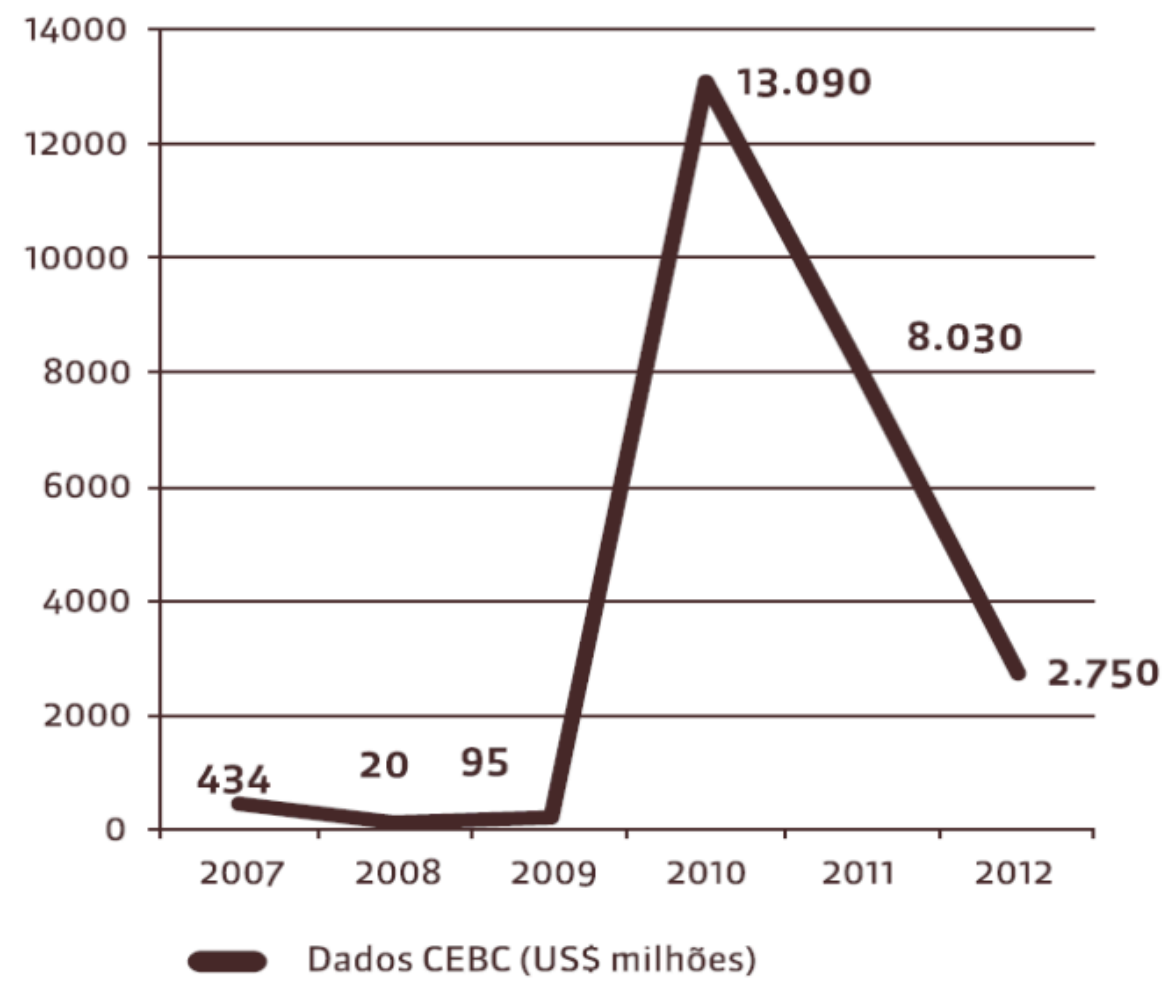

Fonte: Banco Central do Brasil, MOFCOM, Lista Consolidada CEBC, Apud CEBC, 2013, p. 42.

27 A avaliação do ingresso de investimentos na América do Sul permite inferir que o Brasil passou a ocupar uma posição de destaque como recipiendário deste tipo de investimento. No caso brasileiro, o período 2003-2011 caracterizou-se pelo ingresso de US\$ 37,0 bilhões em investimentos chineses (RENAI, 2012). Com efeito, a região Sudeste foi privilegiada por esse modelo de aplicação, destacando-se pelo recebimento de US\$ 24,8 bilhões - entre 2003-2011 - (Imagem 6), o que corresponde a 67,1\% dos investimentos chineses no território nacional ${ }^{3}$, consolidando assim "a relevância do Sudeste" (SANTOS, 2009).

o pragmatismo chinês ao inserir o Brasil em sua base internacional de países fornecedores de recursos naturais é notável, quando avaliamos os investimentos destinados à região Sudeste, tornando-se possível observar que "os setores de Metais e Petróleo, Gás e Carvão corresponderam a 94,15\% do total previsto” (RENAI, 2012). 
Imagem 6 - Investimentos chineses na região Sudeste por setor (2003-2011)

\begin{tabular}{lrr}
\hline Setor & Valor (USS) & Part.(\%) \\
\hline Metais & 13.240 .400 .000 & 53,25 \\
\hline Petróleo, Gás e Carvão & 10.170 .000 .000 & 40,90 \\
\hline Automotivo & 1.106 .800 .000 & 4.45 \\
\hline Máquinas Industriais, Equipamentos e Ferramentas & 210.000 .000 & 0,84 \\
\hline Produtos Químicos & 59.500 .000 & 0,24 \\
\hline Plásticos & 31.900 .000 & 0,13 \\
\hline Serviços financeiros & 18.800 .000 & 0.08 \\
\hline Telecomunicações & 14.300 .000 & 0,06 \\
\hline Duas rodas & 11.300 .000 & 0,05 \\
\hline Serviços Prestados às Empresas & 3.400 .000 & 0,01 \\
\hline Total & $\mathbf{2 4 . 8 6 6 . 4 0 0 . 0 0 0}$ & $\mathbf{1 0 0 , 0 0}$ \\
\hline
\end{tabular}

Fonte: RENAI, 2012

29 Entre os estados da Região Sudeste, o Rio de Janeiro destaca-se como um dos maiores receptores de capitais sínicos, recebendo assim, no período 2003-2011 mais de US\$ 19 bilhões (Imagem 7). A inserção do estado do Rio de Janeiro à rede de investimentos chineses está atrelada à inclusão do território fluminense na base internacional de fornecedores de recursos naturais para a China e a sua relevância nas relações comerciais com esse país asiático que, em 2010 tornou-se o principal parceiro comercial do estado, assim como ao fato de ser a U.F que mais exporta petróleo para a economia chinesa (Imagem 8).

Imagem 7 - Investimentos chineses por estados (em US\$ milhões)

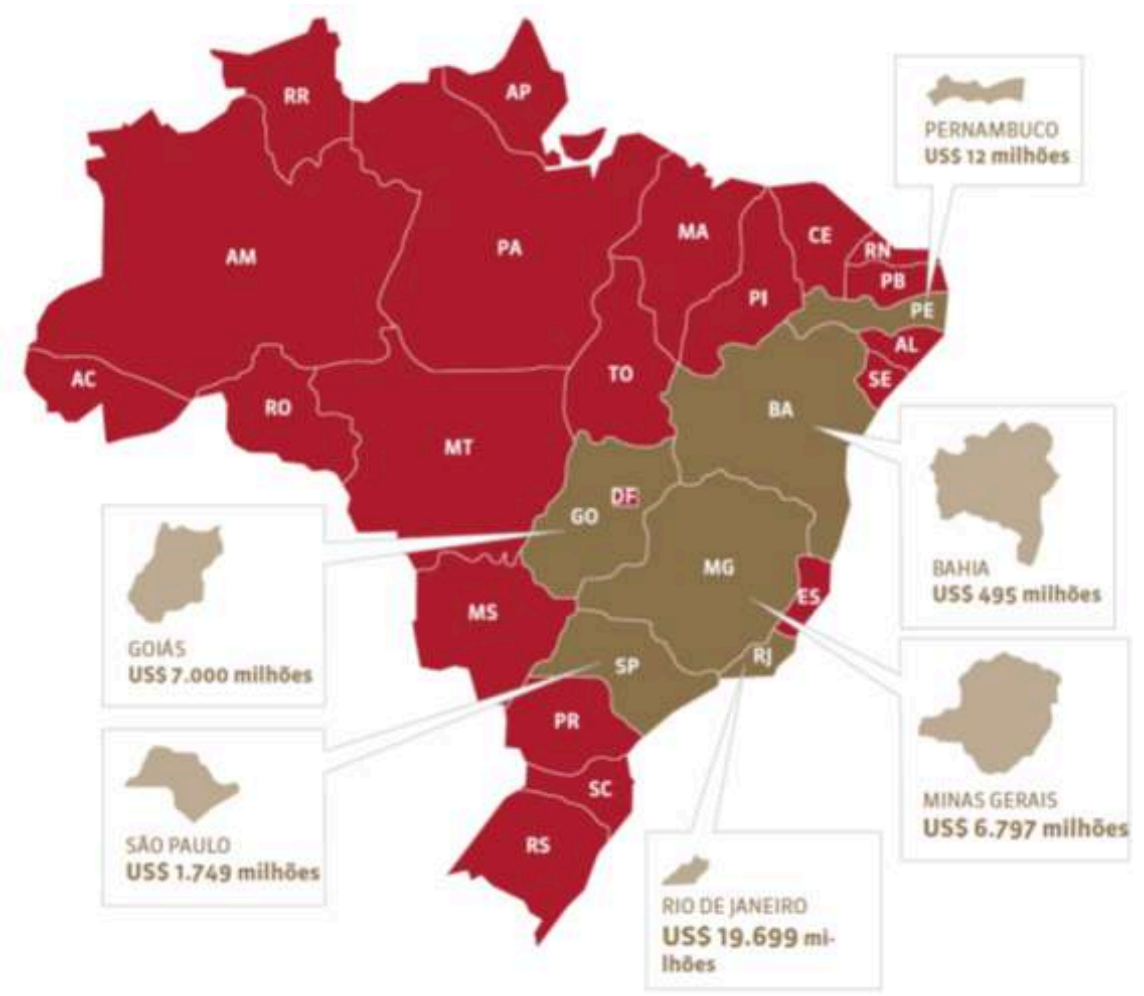

Fonte: CEBC, 2011 
Imagem 8 - Exportações do estado do Rio de Janeiro segundo principais países de destino e seus produtos demandados -2010

\begin{tabular}{|c|c|c|c|}
\hline Paises selecionados e principais produtos exportados & $\begin{array}{r}\text { Valor } \\
\text { (USS milhōes) }\end{array}$ & Participaçăo (\%) & $\begin{array}{l}\text { Participaçăo (\%) } \\
\text { no total do Estado }\end{array}$ \\
\hline China & 4.116 & 100,0 & 20,6 \\
\hline Petróleo e gás natural & 4.053 & 98,5 & \\
\hline Resinas, elastōmeros e fibras artificiais e sintéticas & 29 & 0.7 & \\
\hline Sucata de metal & 6 & 0,1 & \\
\hline Total de produtos selecionados & 4.088 & 99,3 & \\
\hline Estados Unidos & 3.861 & 100,0 & 19,3 \\
\hline Petróleo e gás natural & 3.343 & 86,6 & \\
\hline Produtos siderúrgicos básicos & 125 & 3.2 & \\
\hline Pneus e câmaras & 65 & 1,7 & \\
\hline Total de produtos selecionados & 3.533 & 91,5 & \\
\hline Santa Lúcia & 2.742 & 100,0 & 13,7 \\
\hline Petróleo e gás natural & 2.742 & 100,0 & \\
\hline Total de produtos selecionados & 2.742 & 100,0 & \\
\hline Paises Baixos & 1.316 & 100,0 & 6,6 \\
\hline Petróleo e gás natural & 687 & 52,2 & \\
\hline Outros produtos metalúrgicos & 435 & 33,0 & \\
\hline Óleos combustiveis, inclusive diesel & 67 & 5,1 & \\
\hline Total de produtos selecionados & 1.188 & 90,2 & \\
\hline Chile & 1.274 & 100,0 & 6,4 \\
\hline Petróleo e gàs natural & 1.103 & 86,6 & \\
\hline Automóveis, caminhões e ônibus, inclusive carrocerias & 46 & 3,6 & \\
\hline Laminados de aço & 28 & 2.2 & \\
\hline Total de produtos selecionados & 1.177 & 92,3 & \\
\hline
\end{tabular}

Fonte: FIRJAN, 2011

30 Um dos efeitos da China ter se tornado o primeiro parceiro comercial do Brasil em 2009 sobre a economia fluminense é visível através da imagem acima. Esta permite compreender que a economia chinesa tornou-se o maior destino das exportações fluminenses em 2010, absorvendo 20,6\% de nossas mercadorias, seguida pelos Estados Unidos com 19,3\%. Podendo ser notada a concentração da pauta exportadora para aquele país asiático, onde $98,5 \%$ são de derivados de petróleo.

31 A avaliação acerca do ingresso dos investimentos chineses no território fluminense entre os anos 2004-2013 (Imagem 9) permite compreender que entre os principais investidores estão as empresas estatais chinesas (SOE), embora notemos a presença de investimentos do setor privado chinês, como, por exemplo, a empresa CR Zong-shen do setor automotivo, que busca mercado para os automóveis chineses no Brasil -; bem como investimentos relacionados à área de finanças se façam presentes no período. Entre os setores que mais se destacam na recepção de investimentos chineses temos: o setor de energia, seguido pelo setor de siderurgia, ferroviário e automotivo, respectivamente. No que concerne aos investimentos realizados no setor de energia, o determinante dos investimentos foi à busca de recursos por parte das estatais chinesas, mesma orientação dada aos investimentos no setor siderurgia. 
Imagem 9 - Investimentos chineses anunciados no Rio de Janeiro: 2004-2013

\begin{tabular}{|c|c|c|c|c|c|c|}
\hline Ano & $\begin{array}{l}\text { Empresa } \\
\text { Origem }\end{array}$ & $\begin{array}{l}\text { Valor Anunciado } \\
\text { em USS }\end{array}$ & $\begin{array}{l}\text { Modo de } \\
\text { Entrada }\end{array}$ & Setor & $\begin{array}{l}\text { Estrutura de } \\
\text { Propriedade }\end{array}$ & $\begin{array}{c}\text { Determinante do } \\
\text { Investimento }\end{array}$ \\
\hline 2004 & Sinopec & 240.000 .000 & Green Field & $\begin{array}{c}\text { Energia (patróleo } \\
\text { e Gás) }\end{array}$ & Central SOE & Busca de Mercado \\
\hline 2010 & $\begin{array}{l}\text { Sinopec } \\
\text { Repsol } \\
\text { Brasil }\end{array}$ & 7.109 .000 .000 & $\begin{array}{c}\text { Fusōes \& } \\
\text { Aquisiçôes } \\
\text { (parcial) }\end{array}$ & $\begin{array}{c}\text { Energia (patróleo } \\
\text { e gás) }\end{array}$ & Central SOE & Busca de Recursos \\
\hline 2010 & $\begin{array}{l}\text { Sino-chem } \\
\text { Statoil ASA }\end{array}$ & 3.070 .000 .000 & $\begin{array}{c}\text { Fusões \& } \\
\text { Aquisiçōes } \\
\text { (parcial) }\end{array}$ & $\begin{array}{c}\text { Energia (patróleo } \\
\text { e gás) }\end{array}$ & Central SOE & Busca de Recursos \\
\hline 2010 & $\begin{array}{l}\text { CR Zong- } \\
\text { shen }\end{array}$ & 20.000 .000 & Green Field & Automotivo & Privada & Busca de Mercado \\
\hline 2010 & $\begin{array}{l}\text { Sinopec/ } \\
\text { Cnooc }\end{array}$ & 6.000 .000 .000 & $\begin{array}{c}\text { Fusōes \& } \\
\text { Aquisiçôes } \\
\text { (parcial) }\end{array}$ & $\begin{array}{c}\text { Energia (petróleo } \\
\text { e gás) }\end{array}$ & Central SOE & Busca de Recursos \\
\hline 2010 & Wisco & 3.500 .000 .000 & Joint Venture & Siderurgia & Central SOE & Busca de Recursos \\
\hline 2010 & Sinopec & Nào divulgado & $\begin{array}{c}\text { Fusões \& } \\
\text { Aquisiçōes } \\
\text { (parcial) }\end{array}$ & $\begin{array}{c}\text { Energia (patróleo } \\
\text { e gás) }\end{array}$ & Central SOE & Busca de Recursos \\
\hline 2011 & CNR & 200.000 .000 & $\begin{array}{c}\text { Fusões \& } \\
\text { Aquisições } \\
\text { (completa) }\end{array}$ & Ferroviário & SOE & Busca de Mercado \\
\hline 2011 & Sinopec & 3.500 .000 .000 & $\begin{array}{c}\text { Fusões \& } \\
\text { Aquisicōoes } \\
\text { (parcial) }\end{array}$ & $\begin{array}{c}\text { Energia (Petróleo } \\
\text { e Gás) }\end{array}$ & Central SOE & Busca de Recursos \\
\hline 2012 & $\begin{array}{l}\text { Sinopec } \\
\text { (Anunc) }\end{array}$ & 947.000 .000 & $\begin{array}{c}\text { Fusões \& } \\
\text { Aquisições } \\
\text { (parcial) }\end{array}$ & $\begin{array}{c}\text { Energia (Patróleo } \\
\text { e Gás) }\end{array}$ & Central SOE & Busca de Recursos \\
\hline 2013 & $\begin{array}{l}\text { CNPC e } \\
\text { CNOOC }\end{array}$ & 1.500 .000 .000 & $\begin{array}{c}\text { Fusões \& } \\
\text { Aquisiciōes } \\
\text { (parcial) }\end{array}$ & $\begin{array}{c}\text { Energia (Petróleo } \\
\text { e Gás) }\end{array}$ & Central SOE & Busca de Recursos \\
\hline
\end{tabular}

Fonte: Elaborado pelo autor com base em Oliveira (2012) e CEBC (2013)

O ingresso dos investimentos chineses no país seguem as três principais formas, isto é, fusões e aquisições, joint venture e green field ${ }^{4}$. $O$ ingresso desse tipo de investimento no território fluminense no setor siderúrgico ocorreu em 2010 como joint venture, distinguindo-se dessa forma de ingresso os investimentos no setor energia que seguem o modo de entrada por Fusões \& Aquisições, embora, em 2004 os investimentos anunciados pela empresa Sinopec tenha ingressado sob a modalidade green field como modo de entrada. Compreende-se assim que, a República Popular da China utiliza as três formas, acima mencionadas, para investir no Brasil, mas notam-se especificidades no caso dos investimentos direcionados ao estado do Rio de Janeiro.

Portanto, distintamente da modalidade - green field - de investimento predominante em território nacional entre janeiro de 2007 e junho de 2012 (Imagem 10), os investimentos chineses direcionados ao território fluminense destacam-se no setor energia e na modalidade fusões e aquisições, em especial quando realizados pelas empresas estatais chinesas do setor petrolífero. Assim como a modalidade de ingresso dos investimentos chineses no território fluminense distingue-se da forma de ingresso em escala nacional, o determinante dos investimentos no Brasil - cujo determinante é a busca de mercado (CEBC, 2013) - diferencia-se dos determinantes do ingresso do capital sínico no estado do Rio de Janeiro, sendo direcionado a este estado, mais especificamente na busca por recurso estratégico como o petróleo, evidenciado pelo incremento de investimentos chineses e atuação de estatais chinesas do setor petrolífero no referido estado. 
Imagem 10 - Projetos de investimentos no Brasil por modo (a) e determinante (b) de ingresso Janeiro de 2007 a Junho de 2012

(A)

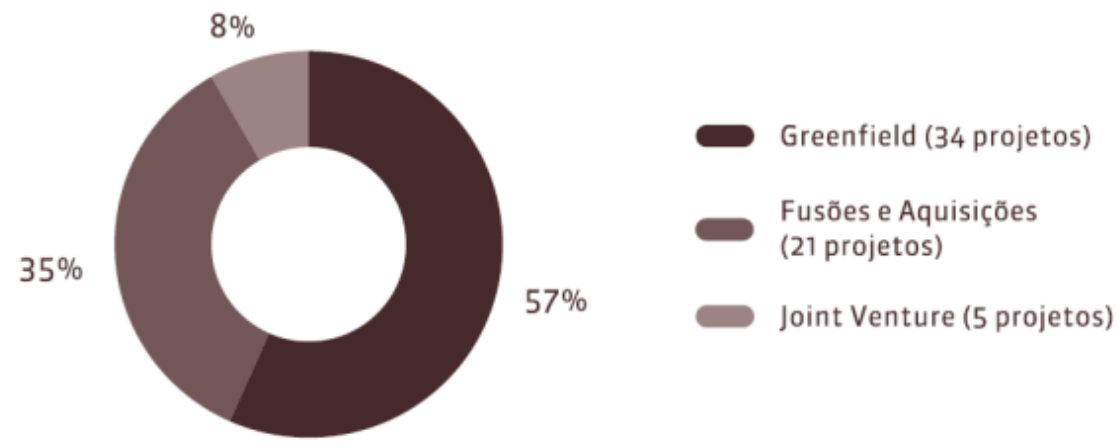

(B)

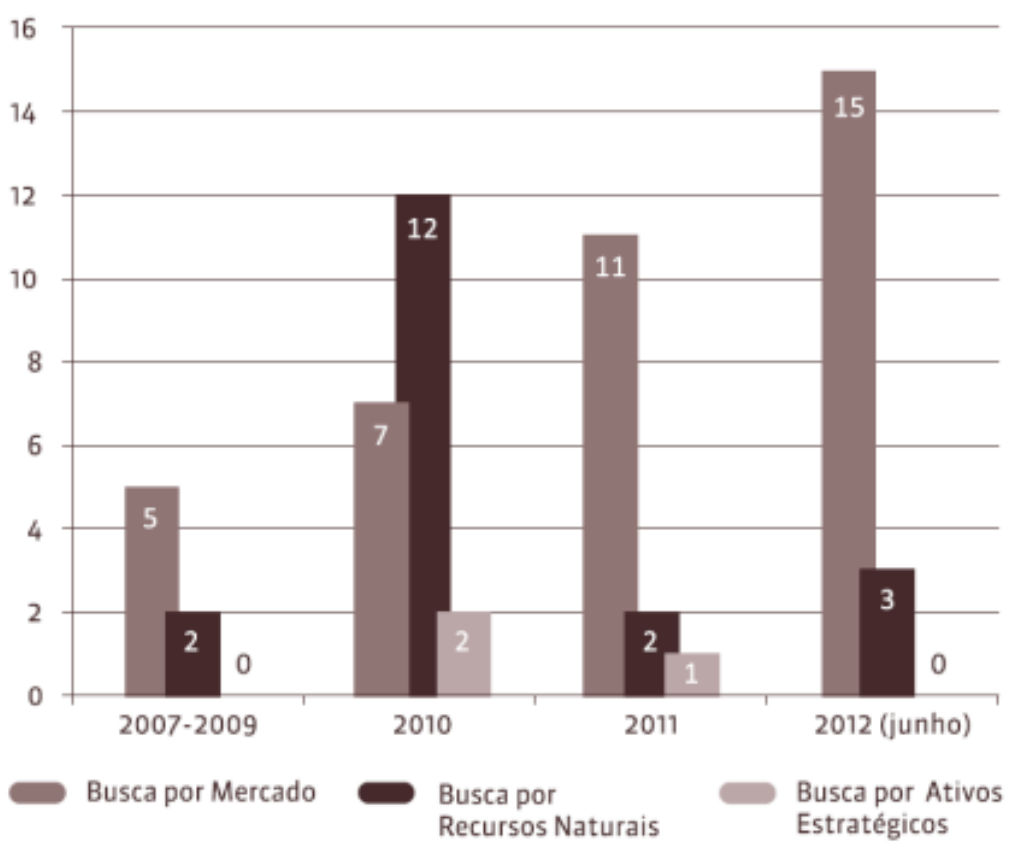

Fonte: CEBC, 2013, p. 48 e 50

\section{A espacialização dos investimentos chineses no estado do Rio de Janeiro e sua atuação na reconfiguração econômica do território fluminense}

Estabelecendo divisas com outros três estados da região Sudeste do Brasil - São Paulo, Minas Gerais e Espírito Santo -, o estado do Rio de Janeiro apresenta atualmente, uma organização político-administrativa formada por 8 regiões de governo e 92 municípios. O território fluminense assiste, no início deste século, a um grande influxo de investimentos, parecendo confirmar a tendência avaliada por estudiosos que, analisando a reestruturação produtiva do território a partir dos anos 1990, 
compreenderam as últimas décadas do século XX como um momento de retomada da trajetória de crescimento econômico do estado, capaz de reverter sua perda de importância na economia nacional após o período de esvaziamento econômico atravessado entre as décadas de 1930-1980 (MELO, 2001; OLIVEIRA, 2008; SILVA, 2012).

Consideramos assim, a década de 1990 como um momento de "retomada da economia fluminense", sendo esta caracterizada pela interiorização dos investimentos e influxo de capital produtivo no território do estado, sem muita participação do capital sínico. Segundo Silva (2012) o influxo de investimentos no território, assim como a instalação de novas plantas industriais são os principais fatores que contribuem de modo especial para a sustentação da economia fluminense e para que esta assista a um processo de retomada econômica a partir da década de 1990, portanto, para Silva (2012):

“A dinamização econômica regional observada a partir de meados dos anos 1990 é consequência direta da modernização/expansão de atividades produtivas ligadas à produção petrolífera e a alguns setores manufatureiros (siderurgia, metalurgia, mecânica, material de transporte e química), que tem ensejado a formação de distintos padrões de desenvolvimento industrial do interior fluminense" (SILVA, 2012, p. 174).

A passagem de um momento caracterizado por poucos investimentos chineses no Brasil, para um período de incremento deste tipo de investimento no país, destacadamente no estado do Rio de Janeiro, permite uma compreensão de que os interesses chineses no território nacional são estratégicos, assim como orientado pelo governo chinês, visando a atender a suas demandas por recursos naturais, sobretudo, as commodities energéticas e minerais ${ }^{5}$. Embora não seja o foco deste trabalho, não cabe aqui desconsiderar o ingresso de investimentos chineses com competitividade no setor industrial brasileiro, como o caso das montadoras chinesas JAC Motors e Cherry em escala nacional e a empresa CR Zong-shen em nível estadual, assim como o anúncio da instalação de uma fábrica de caminhões da Foton em Itatiaia.

No recorte espacial tomado por este estudo, o caso da CISDI em Volta Redonda, os investimentos chineses no Norte Fluminense (Siderúrgica Wisco e um estaleiro), bem como os investimentos da Sinopec, Sinochem, CNPC e CNOOC no Rio de Janeiro evidenciam que o capital sínico segue a lógica de localização dos seus investimentos no território fluminense desencadeada pela reestruturação produtiva do território. A fim de espacializar a localização desses investimentos produtivos é que segue a imagem abaixo: 


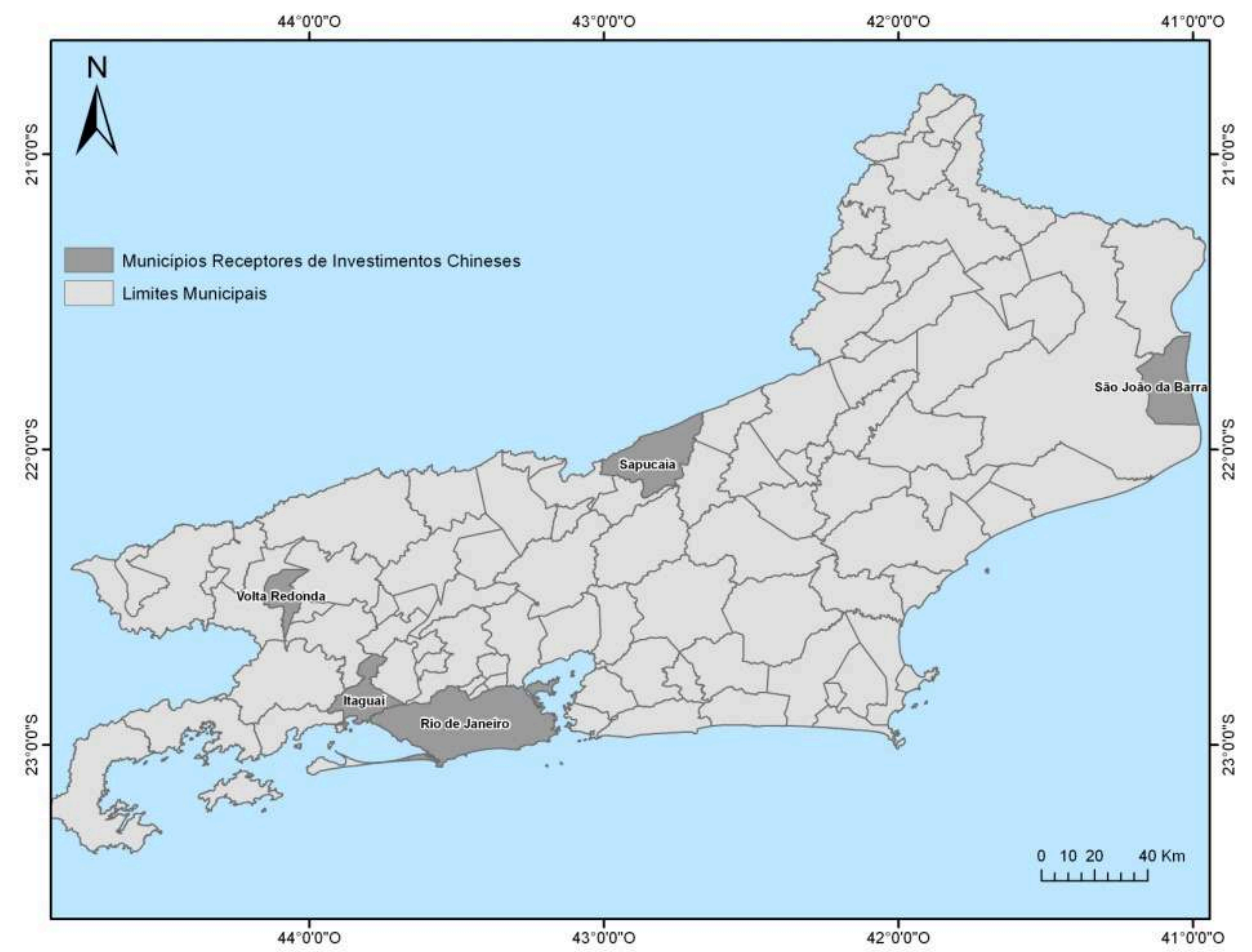

Fonte: Elaborado pelo autor

\section{Considerações Finais}

Compreende-se através deste trabalho que se por um lado os investimentos chineses contribuem para as taxas de crescimento econômico nacional, regional e do estado do Rio de Janeiro, estes quando direcionados ao território fluminense buscam garantir inclusão do Brasil entre os países fornecedores de recursos estratégicos à demanda da economia chinesa por petróleo, evidenciando o processo de transnacionalização do território de que nos fala Santos (1996). Entende-se que a inserção do Brasil entre os países que mais recebem investimentos chineses não conferiu a economia brasileira, um papel extraordinário, visto que até a década de 2010 o Brasil figurava como uma fronteira na América Latina aos investimentos chineses, mas o ingresso do capital sínico no país sob a forma de green field, joint venture e fusões e aquisições na busca por mercado, distingue-se da busca por recursos como a verificada no território do estado do Rio de Janeiro.

Entre os principais fatores para esse influxo de capital sínico fomos capazes de compreender que: I. Na perspectiva geopolítica: o ambiente de concertação política favorável após o restabelecimento do relacionamento Brasil-China conformou um ambiente estável para as relações sino-brasileiras. II. Na perspectiva da conjuntura econômica estadual: a retomada do crescimento econômico do estado do Rio de Janeiro, após a segunda metade da década de 1990, conformou um ambiente econômico favorável e atrativo ao ingresso de investimentos internacionais, sobretudo, de origem chinesa no início do século XXI, passando esse a ser um novo agente na reconfiguração econômica do território fluminense. III. Na perspectiva industrial: o crescimento de 
setores industriais como as atividades extrativas e de transformação, viabilizando a reestruturação produtiva e a espacialização econômico-regional de áreas do território fluminense foram fatores atrativos para aplicação do capital sínico no estado do Rio de Janeiro. IV. Na perspectiva petrolífera: a afirmação do estado do Rio de Janeiro como o maior produtor de petróleo nacional, sobretudo, após a intensificação da exploração da Bacia de Campos, no litoral setentrional do território fluminense, em especial a partir da década de 1990, revelou-se como um fator importante à atratividade dos investimentos chineses, devendo-se atentar a importância desse produto para a economia internacional, em especial a economia da República Popular da China.

\section{BIBLIOGRAFIA}

ALMEIDA, F. R. de F. A Economia Política do Agronegócio. In: Mural Internacional. Ano 2. Rio de Janeiro, 2011.

. O comércio exterior e os interesses do Brasil. Revista CADE-FMJ, v. 11, p. 99-122, 2012.

ARRIGHI, G. Adam Smith em Pequim: Origens e Fundamentos do Século XXI. São Paulo: Boitempo, 2008. . O Longo Século XX: Dinheiro, Poder e a Origem de Nosso Tempo. Rio de Janeiro,

Contraponto, 2012.

CASTRO, I. E. Geografia e Política: território, escalas de ação e instituições. $5^{\mathrm{a}}$ ed. Rio de Janeiro: Bertrand Brasil, 2013.

BONIFACE, P.; VÉDRINE, H. Atlas do Mundo Global. São Paulo: Estação Liberdade, 2009.

HARVEY, D. A Condição Pós-Moderna. São Paulo: Loyola, 1996.

. Espaços de Esperança. São Paulo: Loyola, 2004.

IANNI, O. Teorias da Globalização. 5ª ed. Rio de Janeiro: Civilização Brasileira, 1998.

CEBC. Investimentos chineses no Brasil: uma nova fase da relação Brasil-China. Rio de Janeiro: Maio, 2011.

. Carta Brasil China: Edição 1_março 2011. Rio de Janeiro, 2011.

. Boletim de Investimentos Chineses no Brasil (2012-2013). Rio de Janeiro, 2014.

COSTA, R. H. Globalização e Fragmentação no Mundo Contemporâneo. Niterói: EdUFF, 2001.

FIRJAN. Diagnóstico do comércio exterior do estado do Rio de Janeiro, 2011.

FIORI, J. L. A Nova Geopolítica das Nações e o Lugar da Rússia, China, Índia, Brasil e África do Sul. In: Revista de Economia Heterodoxa, nº 8, ano VI, 2007.

GEIGER, P. P. Tópicos da Economia Política da Globalização. In.: PACHECO, Susana Mara Miranda \& MACHADO, Mônica Sampaio (orgs.). Globalização, políticas públicas e reestruturação territorial. Rio de Janeiro: 7 Letras, 2012.

IPEA, Internacionalização das Empresas Chinesas: as Prioridades do Investimento Direto Chinês no Mundo. Relatório de pesquisa, 2011. 
JABBOUR, E. M. K. Projeto Nacional, Desenvolvimento e Socialismo de Mercado na China de Hoje, (Tese/ USP). São Paulo, 2010.

KISSINGER, H. Sobre a China. Rio de Janeiro, Objetiva, 2011.

KAPLAN, R. D. A Vingança da Geografia: a Construção do Mundo Geopolítico a partir da Perspectiva Geográfica. Rio de Janeiro: Elsevier, 2013.

OLIVEIRA, F. J. G. de. Reestruturação Produtiva: Território e Poder no Estado do Rio de Janeiro. São Paulo, Garamond, 2008.

. O Crescimento Econômico do Rio de Janeiro (2006-2016) Posto a Perder: a Ausência de Políticas Territoriais e de Ordenamento do Território Comprometendo a Possibilidade de Desenvolvimento. In: OLIVEIRA, Floriano José Godinho de.; WERNER, Cláudia Maria Lima.; RIBEIRO, Patrícia Tavares. $1^{\mathrm{a}}$ ed. Rio de Janeiro, Letra Capital, 2013.

OLIVEIRA, A. L. S. de. O investimento direto das empresas chinesas no Brasil- um estudo exploratório. (Dissertação/COPPE/UFRJ). Rio de Janeiro, 2012.

PENHA, E. A.; MARALHAS, R. Política de potência no Brasil e geopolítica energética nuclear. In.: PACHECO, Susana Mara Miranda \& MACHADO, Mônica Sampaio (orgs.). Globalização, políticas públicas e reestruturação territorial. Rio de Janeiro: 7 Letras, 2012.

RENAI. Anúncio de Investimentos Chineses no Brasil (2003-2011). Brasil, 2012.

RIBEIRO, V. L. A Expansão Chinesa e Seus Impactos na África na Primeira Década do Século XXI (Tese/ PPEPI/UFRJ), 2013.

SANTOS, M. O Retorno do Território. São Paulo: Hucitec, 1996.

. A Natureza do Espaço: Técnica e Tempo, Razão e Emoção. São Paulo, Edusp, 2008.

SILVA, R. D. Indústria e desenvolvimento regional no Rio de Janeiro. Rio de Janeiro: FGV, Editora, 2012.

SOBRAL, B. L. B. Metrópole do Rio e Projeto Nacional: Uma Estratégia de Desenvolvimento a partir de Complexos e Centralidades no Território. Rio de Janeiro: Garamond, 2013.

\section{NOTAS}

1. OLIVEIRA, Floriano. Reestruturação Produtiva: Território e Poder no Estado do Rio de Janeiro. São Paulo, Garamond, 2008.

2. Ver IPEA (2011).

3. Relatório Anual de Investimentos - RENAI (2012).

4. Fusões \& Aquisições - compra total ou parcial de empresas situadas no país por um investidor estrangeiro; Joint-Ventures - parcerias estratégicas entre empresas, que envolvem participação acionária das mesmas na criação de uma nova empresa com uma finalidade específica; e Greenfield - construção de instalações totalmente novas no país de destino por um investidor estrangeiro, que tem o controle total da construção e operação dos ativos (CEBC, 2011).

5. As commodities energéticas e minerais compõem percentuais representativos na pauta de exportação de produtos brasileiros para a China conforme destacado por Danielly Silva R. BECARD em O QUE ESPERAR DAS RELAÇÕES BRASIL-CHINA? - Rev. Sociol. Polít., Curitiba, v. 19, n. suplementar, p. 31-44, nov. 2011 - e por Oswaldo Biato JUNIOR em A parceria estratégica SinoBrasileira: origens, evolução e perspectivas (1993-2006) - Brasília: FUNAG, 2010. 


\section{RESUMOS}

O artigo em tela evidencia a inserção do estado do Rio de Janeiro como um dos maiores receptores de investimentos chineses no Brasil. Considerando a atual fase do processo de globalização caracterizada pela desregulamentação dos fluxos capitais e a transnacionalização do território, o artigo resgata o contexto tradicional da China, bem como traça considerações acerca das relações sino-brasileiras, evidenciando a trajetória da República Popular da China (RPC) de receptora à condição de investidor internacional e empreende uma análise acerca da distribuição dos investimentos chineses em diferentes escalas, tratando o influxo deste tipo de investimento no território fluminense, suas formas de ingresso, determinantes e espacialização.

This article puts in evidence the insertion of Rio de Janeiro State like one of the largest receptors of chinese investments in Brazil. Considering the globalization process present phase, featured by the deregulationof capital flow and the territory transnationalization, the article bails out the traditional context of China, and it also makes considerations about the relations between China and Brazil, evidencing the trajectory of China from receptor to the condition of the international investor and performs an analysis about the distribuitionof chinese investments in different scales, treatingthe influxof this type of investments in the fluminense territory, its forms of ingress, determiners and place.

El artículo en cuestión evidencia la inserción del Estado de Rio de Janeiro como uno de los mayores receptores de inversiones chinos en Brasil. Teniendo en cuenta la actual etapa en el proceso de globalización caracterizada por la desreglamentación de los flujos capitales y la transnacionalización del territorio, el artículo rescata el contexto tradicional de China, así como propone consideraciones acerca de las relaciones entre China y Brasil, evidenciando la trayectoria de la República Popular de China (RPC) de receptora a la condición de inversionista internacional y emprende un análisis acerca de la distribución de las inversiones chinas en distintas escalas, tratando el influjo de este tipo de inversiones en el territorio fluminense, sus formas de ingreso, determinantes y espacialización.

L'article suivant souligne la présence de l'État de Rio de Janeiro comme l'un de plus grands récepteurs d'investissements chinois au Brésil. En considérant la déréglementation des flux de capitaux et la trans-nationalisation du territoire qui caractérise la phase actuel de la mondialisation, on souligne la singularité du parcours de la République Populaire de la Chine (RPC) : elle passe de réceptrice à investisseuse internationale. On cherche à montrer la distribution des investissements à différentes échelles à Rio de Janeiro.

\section{ÍNDICE}

Mots-clés: reconfiguration économique, territoire fluminense, investissements chinoises Keywords: chinese investments, economic reconfiguration, fluminense territory Palabras claves: reconfiguración económica, territorio fluminense, las inversiones chinas Palavras-chave: território fluminense, reconfiguração econômica, investimentos chineses 
AUTOR

\section{THIAGO JEREMIAS BAPTISTA}

Professor de geografia na rede pública de ensino estadual no estado do Rio de Janeiro, Mestrando no Programa de Geografia da UERJ, thiagobapt@hotmail.com 